\title{
Karsch-Neugebauer syndrome
}

\author{
INSERM
}

\section{Source}

INSERM. (1999). Orphanet: an online rare disease and orphan drug data base. KarschNeugebauer syndrome. ORPHA:2329

Karsch-Neug ebauer syndrome is a rare syndrome characterized by split-hand and splitfoot deformity and ocular abnormalities, mainly a congenital nystagmus. 